Berkala Ilmu Perpustakaan dan Informasi, Vol. 15, No. 1, Juni 2019, Hal. 60-73 DOI: 10.22146/bip.41785

ISSN 1693-7740 (Print), ISSN 2477-0361 (Online)

Tersedia online di https://jurnal.ugm.ac.id/bip

\title{
Pengaruh pemutaran musik instrumental terhadap kenyamanan membaca pemustaka di Perpustakaan Universitas Muhammadiyah Sukabumi
}

\author{
Nuryaman, Sani Zulviah ${ }^{1}$ \\ ${ }^{1}$ Perpustakaan Universitas Muhammadiyah Sukabumi \\ e-mail:Nuryaman@ummi.ac.id
}

Naskah diterima: 11 Desember 2018, direvisi: 13 Maret 2019, disetujui: 01 April 2019

\begin{abstract}
ABSTRAK
Pendahuluan. Perpustakaan Universitas Muhammadiyah Sukabumi (UMMI) melakukan pemutaran musik intrumental setiap selasa dan jumat pagi dengan tujuan membuat aktivitas membaca pemustaka menjadi lebih nyaman. Berkenaan dengan itu, disusunlah penelitian yang bertujuan mendeskripsikan pengaruh pemutaran musik instrumental terhadap kenyamanan membaca pemustaka.

Metode penelitian. Penelitian ini menggunakan pendekatan kuantitatif dengan metode deskriptif. Pengambilan sampel dari populasi dilakukan dengan teknik simple random sampling, sehingga diperoleh 54 responden. Instrumen pengambilan data menggunakan kuesioner tertutup.

Data analisis. Analisis data menggunakan statistik deskriptif untuk memunculkan gambaran persepsi pemustaka terhadap pemutaran musik instrumental (varibael x) dan kondisi kenyamanan membaca pemustaka (variabel y). Pengujian hipotesis menggunakan piranti lunak IBM SPSS 20 untuk menggambarkan pengaruh variabel $x$ terhadap y.

Hasil dan Pembahasan. Gambaran persepsi pemustaka terhadap pemutaran musik instrumental dan kondisi kenyamanan membaca pemustaka sudah baik, di mana masing-masing skor variabel berjumlah 1.816 dan 1.972 berkategori baik. Pemutaran musik instrumental berpengaruh positif terhadap kenyamanan membaca pemustaka dengan $\mathrm{R}$ square sebesar $16.3 \% . \mathrm{H}_{1}$ diterima yang artinya terdapat pengaruh pemutaran musik instrumental terhadap kenyamanan membaca pemustaka.

Kesimpulan dan Saran. Pemutaran musik instrumetal di perpustakaan berpengaruh positif terhadap kenyamanan membaca pemustaka. Pustakawan dan staf Perpustakaan UMMI dapat mempertahankan inovasi pemutaran musik instrumental, meningkatkan kualitas inovasi dengan penambahan variasi musik instrumental serta penyesuaian volume pemutaran.
\end{abstract}

Kata kunci: Inovasi Perpustakaan; Pemutaran Musik Instrumental; Kenyamanan Membaca

\section{ABSTRACT}

Introduction. Library of Universitas Muhammadiyah Sukabumi (UMMI) plays an instrumental music on Tuesdays and Fridays morning to create nicer atmosphere of reading activities. The paper aims to describe the effects of instrumental music toward users' reading comfort.

Data Collection Method. This research used a descriptive quatitative approach with Likert scale in the surveys. The 54 respondents were gathered by using random sampling.

Analysis Data. The data was analyzed by statistical descriptive to show user's' perceiveness toward playback of instrumental music (variable Y) and user's' reading comfort. The data was analyzed by using SPSS 20.

Results and Discussions. The user's' perceiveness toward the playback of instrumental music and the reading comfort were 1.816 and 1.972 and considered "good". The playback of instrumental music showed a positive effect toward users' reading comfort with R Square $16.3 \%$, and thus $H 1$ was accepted.

Conclusions. The playback of instrumental music in library has positive effect toward users' reading comfort. Librarians should vary the music playlists.

Keywords: Library Inovation; Instrumental's Music Playback; Reading Comfort. 


\section{A. PENDAHULUAN}

Perpustakaan merupakan institusi pengelola informasi tercetak maupun digital. Keseluruhan informasi tersebut dikemas melalui koleksi perpustakaan yang disusun berdasarkan sistem khusus guna memberikan kemudahan dalam proses temu balik informasi. Perpustakaan memiliki fungsi informasi, penelitian, rekreasi, pendidikan, dan kultural. Perpustakaan diharapkan mampu mengoptimalkan fungsinya dengan berorientasi pada kepuasan pengguna (pemustaka). Karena pemustaka merupakan stakeholder yang menjadi tolak ukur keberhasilan perpustakaan, sehingga tidak heran apabila berbagai fasilitas dibangun sebagai upaya untuk mencapai kepuasan pemustaka. Kepuasan tersebut dapat direalisasikan melalui kenyamanan pemustaka ketika membaca untuk memperoleh berbagai informasi yang dibutuhkannya. Khususnya di era teknologi, komunikasi dan informasi, seseorang dituntut untuk memiliki kebiasaan membaca yang baik guna menghindari dampak negatif disinformasi yang merugikan dalam pengambilan keputusan.

Perpustakaan dapat mewujudkan kebiasaan membaca efektif dan konsisten untuk pemustaka dengan strategi menciptakan kondisi membaca yang nyaman bagi pemustaka ketika berada di perpustakaan. Merujuk hasil pengamatan di Perpustakaan UMMI yang memiliki visi sebagai pusat pelayanan informasi dan sumber pengetahuan, secara rutin dilaksanakan pemutaran musik instrumental pukul 08.00-10.00 WIB setiap selasa dan jumat. Hal ini bertujuan memberikan kenyamanan dan ketenangan, sehingga suasana membaca lebih santai, tidak jenuh, serta tidak membosankan. Inovasi ini dilatarbelakangi oleh hasil pengamatan kepala perpustakaan yang menunjukkan kurangnya minat kunjung pemustaka pada waktu pagi menjelang siang, sehingga berdampak pada menurunnya kebiasaan membaca civitas akademika UMMI. Khususnya penurunan angka pemustaka mahasiswa dalam memanfaatkan sumber daya informasi di lingkungan perpustakaan perguruan tinggi. Kondisi demikian merupakan kesenjangan yang perlu diselesaikan, karena tanpa adanya pemanfaatan sumber daya informasi, maka perpustakaan akan dianggap tidak mampu menjalankan fungsi-fungsinya dengan optimal.

Musik sendiri merupakan bagian tak terpisahkan dari kehidupan manusia termasuk membaca. Secara psikologis musik memiliki pengaruh bagi pendengarnya seperti menciptakan suasana penuh kenyamanan dalam menunjang seluruh aktivitas kehidupannya. Bahkan tidak heran apabila rekan sebaya, saudara atau generasi terkini yang bersenangsenang dan berlama-lama belajar disertai pemutaran musik secara terbuka atau menggunakan earphone/headset guna menambah motivasi membaca atau proses belajarnya. Merujuk Seo, Hahner, Gudziol, Scheibe, dan Hummel (2012) diketahui bahwa efek kebisingan dari luar memberikan pengaruh terhadap kinerja seseorang. Karenanya pemutaran musik instrumental diaplikasikan sebagai kebisingan yang diciptakan untuk meningkatkan produktivitas pemustaka dalam membaca. Pemutaran musik instrumental di Perpustakaan UMMI telah berjalan selama kurang lebih dua tahun bersamaan dengan diresmikannya pojok relaksasi sebagai inovasi perpustakaan. Hal ini tentunya menjadi keunikan tersendiri bagi Perpustakaan UMMI, karena tidak semua perpustakaan perguruan tinggi mengembangkan program tersebut.

Selain itu, kondisi tersebut merupakan tuntutan profesionalisme pustakawan sebagai garda pengetahuan dan pekerja informasi yang harus inovatif, kreatif dan adaptif terhadap perkembangan zaman. Dengan semakin dinamisnya perkembangan teknologi, pustakawan tidak hanya berperan sebagai penyedia informasi berupa buku-buku, jurnal, majalah, dan sebagainya. Akan tetapi, pustakawan juga mampu menciptakan kenyamanan yang diminati oleh masing-masing karakteristik pemustakanya. Sebagaimana perubahan makna mutakhir tentang perpustakaan itu sendiri yakni akan terus mengalami perubahan seiring dengan perkembangan teknologi, komunikasi dan informasi (Istiana, Faruk, \& Handayani, 2018). Terlebih dengan hadirnya mental baru dari 
mahasiswa generasi millennial (Generasi Y), maka diperlukan strategi khusus dalam melayani kebutuhan informasinya. Hal ini karena mereka cenderung menuntut percepatan dan pembaharuan dalam aspek lingkungan perpustakaan, sikap pustakawan, serta fisik maupun konten informasi yang ditawarkan. Generasi Y yang lahir pada 1980-an dan awal 1990-an (generasi internet) sangat dipengaruhi kebiasaan membacanya oleh media digital, sehingga perilaku membaca digital relatif meningkat selama lima tahun terakhir. Bahkan hasil penelitian menunjukkan bahwa 69\% anak perempuan dan $65 \%$ anak laki-laki menyukai membaca berbagai konten media elektronik. Karenanya, perancangan layanan perpustakaan idealnya dapat disesuaikan dengan perilaku mahasiswa (Loan \& Shah, 2018; Soroya \& Ameen, 2016).

Pemutaran musik instrumental di Perpustakaan UMMI merupakan inovasi yang dirancang untuk menciptakan lingkungan membaca yang baru, khususnya bagi pemustaka yang sebelumnya tidak terlalu memperhatikan pelayanan perpustakaan. Seperti persepsi masyarakat umum yang masih memandang perpustakaan sebagai gudang buku, sebagai tempat pelarian sumber daya manusia bermasalah, dan tempat sunyi untuk menenangkan diri. Karenanya, inovasi pemutaran musik diciptakan sebagai upaya untuk membangun citra positif perpustakaan di mata khalayak secara bertahap. Musik instrumental sendiri merupakan alternatif yang digunakan masyarakat untuk menenangkan diri, mengendalikan emosi, meningkatkan produktivitas, mengenang masa lalu atau bahkan mengembalikan mood. Begitupun Perpustakaan UMMI sebagai sarana belajar di lingkungan perguruan tinggi memiliki kewajiban dalam menciptakan kondisi senyaman mungkin bagi civitas akademika ketika mereka berada di lingkungan perpustakaan.

Adanya perhatian pemustaka terhadap inovasi perpustakaan, maka akan muncul kepercayaan untuk melibatkan perpustakaan dalam berbagai aktivitas kehidupan. Pemanfaatan musik ini pun merupakan bentuk adaptasi perpustakaan terhadap perkembangan zaman yang semakin menuntut standar pelayanan yang tinggi, sehingga pustakawan memerlukan kesiapan untuk menciptakan inovasi yang menopang setiap perubahan dari dalam maupun dari luar perpustakaan. Hal ini sejalan dengan pernyataan Ranganathan yang salah satu hukumnya menyebutkan bahwa perpustakaan merupakan organisasi yang tumbuh (Sen, 2008). Karenanya berbagai inovasi diciptakan sebagai bukti adanya perkembangan dari perpustakaan terhadap tuntutan zaman. Pemutaran musik instrumental merupakan salah satu bentuk nyata dari inovasi perpustakaan agar tidak ketinggalan zaman.

Berdasarkan penjabaran sebelumnya, maka penelitian tentang pengaruh pemutaran musik instrumental terhadap kenyaman membaca perlu dilakukan, karena hasil penelitiannya dapat digunakan sebagai evaluasi sekaligus rekomendasi terpercaya bagi perpustakaan. Sehingga Perpustakaan UMMI dapat menganalisis kelebihan dan kekurangan dari inovasi yang diimplementasikan, untuk kemudian dijadikan dasar dalam memutuskan kebijakan pelayanan. Hu dan Lee (2016) melakukan penelitian dengan menguji secara statistik persepsi seseorang dari berbagai latar belakang budaya terhadap musik Cina. Hasil penelitiannya kemudian digunakan untuk pengembangan desain perpustakaan musik digital (digital music library/MDL). Penelitian setema pun telah dilakukan sebelumnya oleh Elvandari dan Hermintoyo (2015), Eldaou \& Hassaniyyeh (2016) serta Waas (2017) bertema pengaruh pemutaran musik terhadap aktivitas manusia dan topik kenyamanan membaca di perpustakaan.

Keunikan dalam penelitian ini ialah pengukuran secara spesifik menggunakan konsep AIDDA yang merupakan singkatan dari Attention, Interest, Desire, Decision dan Action (Effendy, 2009). Hal ini bertujuan untuk mengetahui informasi secara spesifik mengenai persepsi pemustaka terhadap pemutaran musik instrumental di Perpustakaan UMMI. Hasil penelitian ini diharapkan mampu menjabarkan persepsi pemustaka terhadap pemutaran musik instrumental dari mulai aspek perhatian 
terhadap musik, sampai dengan tindakan pemustaka ketika membaca disertai pemutaran musik instrumental di perpustakaan. Kemudian pengukuran kenyamanan membaca menggunakan teori aktivitas membaca dari Lasa H.S. dan Suciati (2015), sehingga memberikan gambaran mengenai kenyamanan berbagai aktivitas membaca di lingkungan perpustakaan.

\section{B. TINJAUAN PUSTAKA \\ 1. Konsep Pengaruh Pemutaran Musik Instrumental di Perpustakaan}

Christiani (2015) menerangkan bahwa musik instrumental ialah rangkaian nada yang disusun dan dikombinasikan melalui satu alat musik atau lebih tanpa disertai vokal, sehingga suara musik yang dihasilkan hanya berupa rangkaian nada-nada dari alat musik yang dimainkan. Oleh karena itu, kategori musik ini lebih melibatkan perasaan dan emosi seseorang ketika mendengarkan alunan musiknya. Penjelasan mengenai komposisi musik dipaparkan Hadi (2017) sebagai berikut: (1) ritme (irama) meliputi not, ketukan dan tempo; (2) melodi; (3) harmoni; (4) dinamik; (5) tangga nada; (6) birama; dan (7) timbre.

Keseluruhan unsur musik saling berpadu membentuk alunan musik yang harmoni dan nyaman bagi pendengarnya. Pada mulanya akan timbul sikap perhatian seseorang terhadap musik yang didengarnya, hingga pada akhirnya akan secara terus menerus memutar musik tersebut hingga melibatkannya ke dalam aktivitas sehari-harinya sebagai bentuk tindakan (action) dalam konteks komunikasi. Hal ini tentunya relevan dengan tujuan dari penelitian ini yang bertujuan mengukur persepsi dari mulai perhatian hingga tindakan pemustaka sebagai pengguna perpustakaan, dan sebagai subyek yang bersentuhan langsung dengan pemutaran musik instrumental. Aletta, Lepore, Kostarakonstantinou, dan Kang (2016) mengemukakan bahwa studi pengaruh musik berhubungan dengan mood individu, pengaruh musik, dan sejumlah perilaku yang menjadi parameter produktivitas di tempat kerja atau tempat umum seperti restoran atau pusat perbelanjaan. Karenanya tidak heran apabila musik sering diputarkan di ruang publik termasuk perpustakaan sebagai tempat untuk melaksanakan penelusuran informasi atau pembelajaran.

Adanya aktivitas rutin mendengarkan musik instrumental dapat memberikan pengaruh signifikan terhadap aspek psikologis seseorang. Seperti dibuktikan Guetin et.al (2009) bahwa terdapat pengaruh yang menguntungkan dalam mengurangi simptom kekhawatiran ketika seorang pasien diterapi menggunakan pemutaran musik instrumental Mozart selama empat minggu. Kondisi tersebut diakibatkan adanya stimulus yang diterima oleh telinga dan diproses menjadi sebuah perasaan berupa penerimaan atau penolakan. Penerimaan ini biasanya digambarkan oleh sikap dan perasaan menyenangkan. Bahkan pemutaran musik instrumental Thailand selama sehari sekali setiap bulan mampu menurunkan tekanan darah secara efektif (Im-oun, Kotruchin, Thinsug, \& Mitsungnern, 2018). Selain itu, terapi non-farmakologis seperti musik, apabila digunakan dengan pengobatan farmakologis berpotensi mengurangi gejala kecemasan dan depresi pada orang dewasa dengan demensia ringan (Chan, Wong, \& THayala, 2011; Petrovsky, Cacchione, \& George, 2015).

Thoma et al. (2013) menjabarkan bahwa pemutaran musik memberikan tekanan pada psikobiologi manusia yaitu sistem kelenjar endokrin yang menghasilkan hormon untuk mempengaruhi kerja organ. Karenanya tingkat stres menurun ketika mendengarkan musik instrumental karena adanya penurunan detak jantung yang diakibatkan stimulus dari kelenjar endokrin. Kaitannya dengan aktivitas membaca, ditemukan fakta menarik bahwa "we found the students' reading comprehension in the music task was significantly better than that in the silent task" ( $\mathrm{Su}$ et al., 2017, p. 107). Dapat dimaknai bahwa siswa lebih senang membaca sambil diiringi musik dari pada keheningan. Karenanya tidak heran apabila banyak ditemukan pemustaka yang membaca sambil mendengarkan musik. Krabs, Enk, Teich, dan Koelsch (2015) melakukan eksperimen dengan cara (1) tidak memutarkan musik dan (2) memutarkan musik sesuai durasi khusus. Krabs menyimpulkan bahwa orang-orang lebih senang 
tinggal di tempat yang diputarkan musik. Kondisi ini menunjukkan bahwa pemutaran musik instrumental diharapkan dapat membuat pemustaka merasa nyaman untuk berlama-lama menggunakan jasa layanan informasi di perpustakaan. Selain itu, ketertarikan seseorang terhadap pemutaran musik menunjukkan adanya persepsi yang baik terhadap pemutaran musik di sebuah ruang/tempat beraktivitas.

Konsep persepsi AIDDA digunakan sebagai upaya untuk mengukur persepsi pemustaka dari mulai perhatian hingga aksi mereka terhadap musik instrumental yang diputarkan. AIDDA sebelumnya digunakan Nuryaman (2017) untuk mengetahui persepsi seseorang terhadap perubahan lingkungan di sekitarnya untuk mencapai pemahaman melalui panca inderanya. Pemutaran musik instrumental di Perpustakaan UMMI dapat diukur menggunakan konsep AIDDA, karena musik melibatkan panca indera pendengaran pemustaka. Effendy (2009) menjabarkan bahwa konsep AIDDA meliputi: (1) attention (perhatian), keinginan seseorang untuk mencari dan melihat sesuatu; (2) interest (minat), perasaan ingin mengetahui lebih dalam tentang suatu hal yang menimbulkan daya tarik bagi konsumen; (3) desire (hasrat/keinginan), kemauan yang timbul dari hati tentang sesuatu yang menarik perhatian; (4) decision (keputusan), kepercayaan untuk melakukan sesuatu hal; (5) action (Tindakan), suatu kegiatan untuk merealisasikan keyakinan dan ketertarikan terhadap sesuatu. Dalam konsepnya, disebutkan bahwa AIDDA sering disebut sebagai A-A Procedure, yaitu upaya untuk memunculkan action melalui pembangkitan attention. Karenanya, AIDDA digunakan untuk mengukur sikap pemustaka terhadap inovasi sebagai sesuatu yang baru di lingkungannya.

\section{Konsep Kenyamanan Membaca}

Kenyamanan membaca merupakan aspek penting yang perlu diperhatikan pustakawan, karena membaca merupakan cara pemustaka memperoleh informasi. Membaca sendiri merupakan aktivitas yang melibatkan fisik dan psikologis pemustaka dalam waktu yang bersamaan, sehingga tidak heran apabila seseorang mudah terganggu atau buyar konsentrasinya ketika tengah asyik membaca. Dalam proses membaca seseorang bisa saja larut dalam alur cerita, atau membayangkan secara imajinatif mengenai fenomena-fenomena yang tertuang dalam buku bacaan. Terdapat beberapa faktor yang menimbulkan rasa nyaman di perpustakaan, dan musik merupakan faktor eksternal yang dapat membuat pemustaka merasa nyaman ketika membaca. Faktor kenyamanan tersebut dapat diwujudkan melalui penciptaan lingkungan belajar sesuai minat pemustaka agar mereka mendapatkan pengalaman berharga (Akyol, Cakiroglu, \& Kuruyer, 2014). Kondisi ini menunjukkan bahwa pustakawan idealnya menciptakan lingkungan yang sesuai dengan karakteristik pemustaka.

Seiring dengan perkembangan teknologi informasi (TI), kebiasaan membaca anak-anak maupun orang dewasa mengalami pergeseran makna. Awalnya, seseorang dijuluki pintar karena membaca buku yang tebal dan berat di ruangan sempit serta penuh keheningan. Namun kini, aktivitas membaca tidak hanya identik dengan buku, tetapi berhubungan dengan keragaman koleksi digital, penggunaan akses internet dan faktor psikologi. Mozuraite (2014) mengemukakan bahwa sejak akhir abad ke-20, aktivitas membaca mengalami perubahan akibat pengaruh TI, banjir informasi elektronik, semakin populernya WWW dan adanya kemungkinan menerima informasi berbeda di waktu yang bersamaan. Kondisi ini menunjukkan bahwa pustakawan idealnya memperhatikan kebiasaan membaca pemustaka agar ketersediaan koleksi dan sarana perpustakaan dapat menyesuaikan dengan tuntutan zaman. Seperti pemustaka mahasiswa di universitas, mereka lebih senang membaca artikel akademik di layar daripada mencetaknya, karena $82 \%$ mahasiswa mempertimbangkan biaya cetak. Mahasiswa akan mencetak artikel tersebut ketika benarbenar dibutuhkan untuk penunjang tugas dengan persentase 77\% (Vandenhoek, 2013).

Pemaparan sebelumnya menunjukkan bahwa pemustaka mengalami perubahan yang 
signifikan akibat perkembangan TI di perpustakaan. Penggunaan jurnal elektronik sudah lazim digunakan pemustaka mahasiswa di perguruan tinggi. Mahasiswa biasanya diinstruksikan oleh dosen agar mereka membaca jurnal nasional dan internasional dengan jumlah tertentu. Tujuannya meningkatkan kualitas informasi yang dihasilkan seperti makalah, artikel jurnal, proyek inovasi, dan tugas akhir. Karenanya, perpustakaan harus melakukan pengaturan fasilitas dan ruangan yang menghadirkan kenyamanan bagi pemustaka. Owusu-acheaw dan Larson (2014), menegaskan bahwa mayoritas mahasiswa menyadari akan pentingnya membaca, sehingga $62 \%$ dari mereka senantiasa membaca untuk kepentingan kelulusan ujian. Selain itu, penelitian merekomendasikan agar dosen membatasi pembuatan handout, sehingga mendorong mereka untuk menggunakan perpustakaan. Mahasiswa dituntut memiliki pengetahuan tentang bidang studinya dari berbagai sudut pandang keilmuan. Pengetahuan ini diperoleh dengan membaca sejumlah sumber informasi di perpustakaan, karena dengan membaca mahasiswa akan menemukan, menganalisis, menyimpulkan bahkan mengkritisi kesenjangan. Sebagaimana Naveed-e-Sehar \& Ghaffar (2018), membaca merupakan seni mengekspos pengetahuan tentang dunia melalui decoding kata-kata tertulis.

Aktivitas membaca memerlukan keteguhan hati dan kontinuitas guna memperoleh informasi yang sesuai dengan kebutuhan. Rasa nyaman dibutuhkan dalam aktivitas membaca karena tanpa adanya kenyamanan dalam membaca, dapat dipastikan informasi yang diperoleh pun tidak dapat dicerna. Pada akhirnya, tujuan pemustaka membaca buku menjadi membuang waktu. Hal ini merugikan pihak pemustaka yang menggunakan jasa perpustakaan karena mereka telah menyianyiakan waktu dan tenaga untuk bisa datang ke perpustakaan. Pustakawan idealnya menciptakan inovasi untuk kenyamanan membaca di lingkungan perpustakaan. Sebagaimana Lopatovska dan Sessions (2016) bahwa aktivitas membaca mahasiswa khususnya dalam mengerjakan tugas akademik memerlukan kombinasi membaca "deep" and "surface" pada koleksi tercetak atau digital. Adanya kenyamanan membaca yang dirasakan pemustaka, maka mereka dapat dengan mudah menemukan dan menyerap informasi dari koleksi perpustakaan.

Berdasarkan pernyataan Lasa (2015) diketahui bahwa aktivitas membaca meliputi (1) membaca acak (browsing), yaitu aktivitas membaca dengan tujuan memperoleh informasi baru seperti sekedar melihat-lihat judul buku, majalah, kamus, ensiklopedia, karya tugas akhir dan sejenisnya; (2) membaca banding-banding (syntopical reading), yaitu bertujuan penyusunan rencana kegiatan ilmiah seperti membuat artikel atau jurnal; (3) membaca cepat (rapid reading), yaitu bertujuan membaca secara cepat mengenai bidang tertentu (concern), karena sudah terbiasa; (4) membaca coba-coba (trial reading), bertujuan untuk menentukan bahan bacaan yang akan digunakan; (5) membaca dengan sorotan (scanning reading), bahan bacaan yang akan digunakan; yaitu bertujuan mencari topik dalam suatu koleksi misalnya melalui daftar isi, maupun indeks; (6) membaca lompat-lompat (skimming reading), yaitu bertujuan membaca sepintas bagian kata pengantar, daftar isi, indeks, bab, resensi secara sekilas, sehingga apabila tertarik akan membaca secara intensif; dan (7) membaca secara kritis (critical reading), yaitu bertujuan melakukan penilaian tentang topik tertentu dalam bahan bacaan, sehingga koleksi dibaca dengan pelan, konsentrasi, dan terkadang repetisi beberapa kalimat serta paragraf.

Di Abad ke-21 telah lahir gawai pintar (smartphone) yang mengubah kebiasaan membaca manusia dengan cepat (Shimray, Keerti, \& Ramaiah, 2015). Kondisi ini ditandai dengan munculnya sumber informasi elektronik yang menyajikan alternatif bahan bacaan bagi pemustaka. Setiap pemustaka selalu berusaha membaca secara efektif dan efisien agar tercapainya informasi yang sesuai dengan tingkat kepentingan. Bahkan sebagian pemustaka mengharapkan terciptanya ketenangan ketika berada di perpustakaan, 
karena untuk menyerap informasi dibutuhkan konsentrasi yang tinggi.

\section{METODE PENELITIAN}

Penelitian ini menggunakan pendekatan kuantitatif dan metode deskriptif karena lebih menekankan pada pengukuran secara obyektif, dan menampilkan hasil penelitian berupa angka-angka dengan analisis menggunakan statistik (Sugiyono, 2016). Subjek penelitian merupakan pemustaka yang pernah membaca dan mendengarkan musik instrumental di perpustakaan yaitu mahasiswa, dosen dan staf Universitas Muhammadiyah Sukabumi. Objek penelitian ini ialah persepsi pemustaka melalui konsep AIDDA dan kondisi kenyamanan membaca pemustaka. Sampel berjumlah 54 responden yang diambil melalui simple random sampling yaitu proses pengambilan sampel secara acak dari populasi. Selanjutnya pengumpulan data melalui kuesioner tertutup dengan pilihan jawaban skala Likert. Analisis data menggunakan uji Regresi Linear Sederhana dan Anova melalui IBM SPSS 20, karena mencari pengaruh musik sebagai treatment terhadap kenyamanan membaca. Adapun hipotesis penelitian dapat dipaparkan sebagai berikut:

$\mathrm{H}_{0}=$ tidak adanya pengaruh pemutaran musik instrumental terhadap kenyamanan membaca pemustaka di perpustakaan Universitas Muhammadiyah Sukabumi.

$\mathrm{H}_{1}=$ terdapat pengaruh pemutaran musik instrumental terhadap kenyamanan membaca pemustaka di perpustakaan Universitas Muhammadiyah Sukabumi.

\section{HASILDAN PEMBAHASAN}

Pada praktiknya, pemustaka di Perpustakaan UMMI memiliki aktivitas membaca yang cukup intensif dalam rangka memenuhi kebutuhan informasi untuk tugas kuliah, rekreasi dan penulisan tugas akhir. Apabila merujuk hasil rekapitulasi layanan baca di tempat dari September 2017 sampai dengan Maret 2018 dapat diketahui melalui Gambar 1.

Gambar 1 menunjukkan adanya peningkatan minat baca pemustaka dari September menuju Maret 2018. Nilai persentase signifikan terlihat pada februari menjelang maret yang mengindikasikan adanya kepercayaan pemustaka dalam menggunakan jasa Perpustakaan UMMI sebagai sumber informasi dan pengetahuan. Sehubungan dengan itu, pustakawan harus mempertahankan sekaligus meningkatkan kualitas layanan agar terciptanya suasana membaca yang nyaman bagi seluruh pemustaka. Hasil dalam upaya memperoleh hasil yang akurat dan spesifik maka perlunya pemaparan hasil dan pembahasan penelitian yang dijabarkan sebagai berikut:

\section{Gambaran Pemutaran Musik Instrumental}

Adapun kategori gambaran pemutaran musik instrumental disajikan dalam Gambar 2. Gambar 2 menunjukkan bahwa pemutaran musik instrumental di perpustakaan dianggap "baik" oleh pemustaka. Hal ini dibuktikan dengan total skor 1.816 yang berada pada kategori baik (B). Pemustaka cenderung memiliki perhatian, keinginan, minat, hasrat dan keputusan yang baik terhadap pemutaran musik instrumen setiap Selasa dan Jumat. Secara spesifik dapat dilihat persepsi pemustaka menggunakan konsep AIDDA dengan masingmasing perolehan rata-rata skor untuk attention: 333, interest: 343.67 , desire: 217, decision: 271.67, dan action: 237. Dapat diketahui bahwa skor tertinggi dimiliki oleh aspek interest dan skor terendah ialah aspek desire. Kondisi menunjukkan bahwa pemustaka memiliki ketertarikan yang relatif lebih tinggi terhadap pemutaran musik instrumental di perpustakaan. Kemudian skor terendah ini mengindikasikan bahwa pemustaka tidak sepenuhnya menginginkan musik instrumental terintegrasi dalam keseluruhan aktivitas kehidupannya. Pemustaka menggunakan musik instrumental sesuai dengan kebutuhan dan mood mereka masing-masing.

Aletta et al. (2016) menegaskan bahwa musik yang diputarkan berhubungan dengan mood individu bahkan dijadikan parameter produktivitas di tempat kerja. Melihat kondisi 
pemustaka UMMI yang didominasi generasi millenial, maka pemutaran musik di Perpustakaan UMMI cukup menarik perhatian (attention) pemustaka ketika mereka mendengarkannya. Hal ini karena musik merupakan inovasi berbasis pemanfaatan teknologi sesuai karakteristik generasi millenial, sehingga mereka relatif berpikir menyenangkan ketika musik diputarkan di perpustakaan. Berdasarkan pernyataan Thoma et al. (2013), diketahui bahwa pemustaka UMMI mengalami tekanan psikobiologi yang menyebabkan kelenjar endokrinnya aktif ketika mendengarkan musik instrumental. Pemustaka merasakan pengaruh musik instrumental seperti mampu mengatur emosi dan membuat suasana menjadi lebih rilex. Hal ini sejalan dengan tujuan pemutaran musik instrumental di perpustakaan guna memberikan kenyamanan sekaligus relaksasi bagi pemustaka.

Pemustaka memiliki ketertarikan (interest) terhadap pemutaran musik instrumental di perpustakaan, karena musik tersebut dianggap mampu menarik pemustaka untuk mendengarkannya secara terus-menerus ketika membaca. Pemustaka senantiasa menunggu musik instrumental diputar, bahkan mereka memiliki ketertarikan untuk memiliki musik instrumen yang diputar. Apabila merujuk penjelasan Guetin et al. (2009), mengindikasikan bahwa pemustaka UMMI menikmati pemutaran musik instrumental setiap minggunya, karena bisa jadi menurunkan simptom kekhawatiran pemustaka ketika akan atau sedang mengerjakan tugas. Sikap menunggu pemustaka pun mendukung hasil penelitian Krab et al. (2015) bahwa pemustaka lebih senang tinggal di tempat yang diputarkan musik, karena mereka merasakan semacam perlakuan yang berpengaruh terhadap psikologisnya. Sikap ini didukung pula oleh keputusan dan aksi (decision and action) pemustaka yang memiliki skor relatif tinggi.

Meski demikian, nilai rata-rata skor terendah yaitu hasrat (desire) yang artinya pemustaka belum sepenuhnya menjadikan musik instrumental sebagai bagian dari aktivitas membaca di mana saja. Hasrat merupakan keinginan kuat untuk mendapatkan sesuatu yang dianggap mampu memenuhi kebutuhan hidupnya. Keinginan kuat ini biasanya ditunjukkan dengan usaha/kerja keras individu untuk meraihnya dengan berbagai cara. Pemutaran musik ini ialah treatment dengan tujuan khusus dan kontinuitas, sehingga tidak heran apabila pemustaka memiliki hasrat yang rendah terhadap musik instrumental. Hasrat pemustaka UMMI terhadap pemutaran musik instrumental, diketahui bahwa hasrat tersebut belum muncul signifikan dari pemustaka seperti adanya permintaan khusus ke pustakawan atau staf untuk memutarkan musik di luar jadwal yang ditentukan.

\section{Gambaran Kenyamanan Membaca}

Adapun kategori kondisi pemutaran musik instrumental akan disajikan melalui gambar 3 . Gambar 3 menunjukkan bahwa kenyamanan membaca di perpustakaan sudah "baik" untuk pemustaka yang dibuktikan dengan total skor sebesar 1.972 yang berada pada kategori baik (B). Dengan demikian pemustaka merasakan kenyamanan dalam keseluruhan aktivitas membaca di perpustakaan (Lasa H.S. \& Suciati, 2015). Kondisi tersebut menunjukkan bahwa comport atau kenyamanan merupakan aspek penting yang perlu diperhatikan, karena musik merupakan salah satu faktor eksternal yang berpengaruh terhadap kenyamanan membaca. Pentingnya pengaturan lingkungan ditegaskan Akyol et al. (2014) bahwa untuk memberikan pengalaman berharga kepada pemustaka, maka pustakawan harus menciptakan lingkungan belajar sesuai karakteristik pemustaka. Khususnya dengan semakin berkembangnya TI yang memberikan pengaruh signifikan terhadap kebiasaan membaca pemustaka. Misalnya kebiasaan generasi millenial yang terbiasa beraktivitas dengan bantuan teknologi, termasuk aktivitas membaca, memerlukan pengaturan fasilitas fisik maupun aspek psikologi untuk kenyamanan membaca.

Apabila merujuk "kenyamanan membaca" yang sudah "baik", mengindikasikan bahwa musik merupakan salah satu faktor yang mempengaruhi kenyamanan membaca, sehingga pemutaran musik instrumental memiliki pengaruh khusus terhadap pemustaka. 
Terciptanya kenyamanan membaca yang "baik" bagi pemustaka secara langsung memberikan kontribusi terhadap peningkatan citra positif layanan perpustakaan. Aktivitas membaca pemustaka sangat variatif, bergantung pada masing-masing kebutuhan informasinya. Pemustaka dengan kepentingan untuk mengerjakan tugas akademik seperti pembuatan makalah, presentasi, resensi, dan tugas akhir memerlukan teknik membaca secara "deep" and "surface" (Lopatovska \& Sessions, 2016). Apabila merujuk Lasa dan Suciati (2015) terdapat tujuh aktivitas membaca, dan penyelesaian tugas akademik termasuk ke dalam jenis membaca banding-banding (syntopical reading), membaca cepat (rapid reading), dan membaca secara kritis (critical reading). Ketiga kategori tersebut memerlukan konsentrasi dan ketenangan untuk menghasilkan produk informasi yang berkualitas tinggi. Karenanya, pemutaran musik instrumental diimplementasikan sebagai upaya untuk memberikan kenyamanan dan ketenangan kepada pemustaka.

\section{Gambaran Pengaruh Pemutaran Musik Instrumental terhadap Kenyamanan Membaca}

Berdasarkan tabel 1 diketahui bahwa koefisien determinasi (R square) sebesar 0,163 $\%$ yang menunjukkan pengaruh variabel bebas X (Pemutaran Musik Instrumental) terhadap variabel terikat $\mathrm{Y}$ (Kenyamanan Membaca) adalah $16.3 \%$.

Berdasarkan tabel 2 diketahui bahwa nilai $F$ hitung $=10,100$ dengan tingkat signifikansi sebesar $0,002<0,005$ maka model regresi menunjukkan adanya pengaruh variabel $\mathrm{X}$ terhadap Y.

Berdasarkan tabel 3 diketahui bahwa nilai Constant (a) sebesar 11,946 dan koefisien regresi (b) sebesar 0,341, sehingga persamaannya regresinya yaitu $\mathrm{Y}=\mathrm{a}+\mathrm{bX} \quad \mathrm{Y}=$ $11,946+0,341 X$. Persamaan tersebut menunjukkan bahwa nilai konstanta Y sebesar 11,946. Selanjutnya koefisien regresi $X$ sebesar 0,341 menyatakan bahwa setiap penambahan 1 $\%$ nilai "Pemutaran Musik Instrumental", maka nilai "Kenyamanan Membaca" bertambah sebesar 0,341. Koefisien regresi yang bernilai positif menegaskan bahwa arah pengaruh "Pemutaran Musik Instrumental" terhadap "Kenyaman Memabaca" bernilai positif. Sejalan dengan hasil uji Anova, maka perolehan nilai signifikansi $0,002<0,005$, sehingga dapat disimpulkan bahwa variabel $\mathrm{X}$ berpengaruh terhadap Y. Begitupun $\mathrm{t}_{\text {hitung }}=3,3178>\mathrm{t}_{\text {tabel }}=$ $2,00488 / 2,0049$ (diambil dari $t_{\text {tabel }} \mathrm{df}=41-80$ ).

Berdasarkan penjabaran sebelumnya diketahui bahwa $X$ berpengaruh positif terhadap Y sebesar $16.3 \%$. Memberikan gambaran bahwa $\mathrm{H}_{0}$ ditolak (tidak adanya pengaruh pemutaran musik instrumental terhadap kenyamanan membaca pemustaka di perpustakaan Universitas Muhammadiyah Sukabumi), sedangkan $\mathrm{H}_{1}$ diterima (terdapat pengaruh pemutaran musik terhadap kenyamanan membaca pemustaka di perpustakaan Universitas Muhammadiyah Sukabumi). Hasil tersebut sejalan dengan hasil penelitian Elvandari dan Hermintoyo (2015), Eldaou \& Hassaniyyeh (2016), serta Waas (2017), bahwa terdapat pengaruh positif antara pemutaran musik terhadap kenyamanan membaca pemustaka (pengguna) di perpustakaan. Di mana musik instrumental mampu mengurangi stres, memberikan kenyamanan dan meningkatkan konsentrasi dalam membaca serta menyerap informasi pada koleksi Perpustakaan UMMI. Maknanya, pemutaran musik instrumental di perpustakaan memberikan kontribusi positif terhadap psikobiologi dan psikologis pemustaka yang mendengarkannya ketika melakukan aktivitas membaca di perpustakaan.

Chan et al. (2011), Thoma et al. (2013) dan Petrovsky et al. (2015) menjelaskan bahwa musik merupakan jenis terapi non-farmakologi yang mampu mengurangi gejala stress seseorang ketika menghadapi sebuah situasi. Termasuk pemustaka mahasiswa yang diliputi berbagai tugas akademik memerlukan suasana lingkungan yang tenang dan nyaman untuk menyelesaikan segala bentuk pekerjaan. Pengaturan lingkungan perpustakaan sangat penting diperhatikan pustakawan karena pemustaka senantiasa mengalami perubahan dalam kebiasaan membaca (Mozuraite, 2014). 
Naveed-e-Sehar dan Ghaffar (2018), menegaskan bahwa membaca merupakan seni mengekspos pengetahuan tentang dunia melalui decoding kata-kata tertulis. Proses penyerapan informasi (decoding) tersebut merupakan proses penting yang perlu diperhatikan pustakawan agar pemustaka memperoleh informasi sesuai harapan. Salah satunya ialah pemutaran musik instrumental di perpustakaan untuk memberikan kenyamanan membaca kepada pemustaka, sehingga proses penyerapan informasi dapat berlangsung dengan optimal.

Pengaruh positif ini mengindikasikan bahwa pemutaran musik instrumental mampu meningkatkan produktivitas membaca mahasiswa. Sebagaimana Aletta et al. (2016) bahwa musik dapat dijadikan sebagai parameter produktivitas kerja, karenanya musik sering diputarkan di ruang publik. Kondisi ini tersebut terbukti dengan hasil penelitian ini, karena perpustakaan sebagai sarana publik untuk civitas akademika UMMI memiliki pengaruh positif terhadap kenyamanan membaca. Program inovasi ini dianggap berhasil dan mencapai tujuan yang ditetapkan. Pustakawan dan staf perpustakaan dapat menjaga sekaligus meningkatkan kualitas pemutaran musik instrumental di perpustakaan sesuai dengan tuntutan pemustaka serta optimalisasi pemanfaatan TI agar perpustakaan tetap eksis dari zaman ke zaman.

\section{E. KESIMPULAN}

Pengaruh pemutaran musik instrumental terhadap kenyamanan membaca pemustaka di Perpustakaan UMMI, dan dengan pembuktian hasil uji hipotesis yakni $\mathrm{H}_{0}$ ditolak dan $\mathrm{H}_{1}$ diterima. Artinya pemutaran musik instrumental memiliki pengaruh positif terhadap kenyamanan membaca pemustaka. Hal ini didukung pula dengan adanya persepsi yang baik dari pemustaka terhadap pemutaran musik instrumental serta kondisi kenyamanan membaca yang baik. Dengan demikian, pemutaran musik instrumental merupakan inovasi Perpustakaan UMMI yang sudah berjalan dengan baik, karena memberikan pengaruh positif kepada pemustaka. Adapun rekomendasi dalam penelitian ini yaitu (1) adanya pemilihan musik lebih variatif seperti akustik dan musik instrumental karya Bethoven atau Kenny G; dan (2) adanya pengaturan terhadap volume pemutaran musik.

\section{DAFTAR PUSTAKA}

Akyol, H., Cakiroglu, A., \& Kuruyer, H. G. (2014). A study on the development of reading skills of the students having difficulty in reading: Enrichment reading program 1. International Electronic Journal of Elementary Education, 6(2), 199-212.

Aletta, F., Lepore, F., Kostara-konstantinou, E., \& Kang, J. (2016). An experimental study on the influence of soundscapes on people's behaviour in an open public space. Applied Science, 6(276), 1-12. https://doi.org/ 10.3390/app6100276

Chan, M. F., Wong, Z. Y., \& THayala, N. V. (2011). The effectiveness of music listening in reducing depressive symptoms in adults: A systematic review. Complementary Therapies in Medicine, 19(6), 332-348. https://doi.org/10.1016/j.ctim.2011.08.003

Christiani, M. (2015). Pengaruh musik instrumental terhadap hasil belajar matematika siswa kelas 1 sekolah dasar. Didaktika Jurnal Ilmu Pembelajaran KeSDan, 3(1), 117-128.

Effendy, O. U. (2009). Komunikasi: Teori dan praktek. Bandung: Remaja Rosdakarya.

Eldou, B. M. N., \& Hassaniyyeh, M. (2016). The influence of classical music on the concentration and performance levels of students with mild. International Journal of Arts \& Sciences, 07(05), 297-312.

Elvandari, D. R., \& Hermintoyo. (2015). Pengaruh musik klasik terhadap kenyamanan pemustaka di UPT Perpustakaan Universitas Pancasakti kota Tegal Jawa Tengah. Jurnal Ilmu Perpustakaan,3(1), 1-8. 
Guetin, S., Portret, F., Picot, M. C., Pommié, C., Messaoudi, M., Djabelkir, L., ... Touchon, J. (2009). Effect of music therapy on anxiety and depression in patients with Alzheimer's type dementia: Randomised, controlled study. Dementia and Cognitive Disorder, 28(1), 36-46. https://doi.org/ $10.1159 / 000229024$

Hadi, A. (2017). Pengertian, fungsi, dan unsur seni musik. Retrieved from http://www.softilmu.com/2015/11/Pengert ian-Fungsi-Unsur-Unsur-Seni-MusikAdalah.html

Hu, X., \& Lee, J. H. (2016). Towards global music digital libraries a cross-cultural comparison on the mood of Chinese music. Journal of Documentation, 72(5), 858-877. https://doi.org/10.1108/JD-01-2016-0005

Im-oun, S., Kotruchin, P., Thinsug, P., \& Mitsungnern, T. (2018). Complementary therapies in medicine effect of Thai instrumental folk music on blood pressure: A randomized controlled trial in stage-2 Hypertensive patients. Complementary Therapies in Medicine, 39(January), 43-48. https://doi.org/10.1016/ j.ctim.2018.05.014

Istiana, P., Faruk, \& Handayani, S. (2018). Perubahan makna perpustakaan. Berkala Ilmu Perpustakaan dan Informasi, 14(2), 204-213. https://doi.org/10.22146/ bip. 37876

Krabs, R. U., Enk, R., Teich, N., \& Koelsch, S. (2015). Autonomic effects of music in health and crohn's disease: The impact of isochronicity, emotional valence, and tempo. PLOS ONE, 10(5), 1-31. https://doi.org/10.1371/journal.pone.0126 224

Lasa H.S., \& Suciati, U. (2015). Kamus kepustakawanan Indonesia (Revisi). Yogyakarta.

Loan, F. A., \& Shah, R. (2018). Survey of the literature reading habits and preferences of adolescents: A study of a public school in India. Libres, 27(2), 80-96.
Lopatovska, I., \& Sessions, D. (2016). Understanding academic reading in the context of information-seeking. Library Review, 66 (89), 502-518. https://doi.org/10.1108/LR-03-2016-0026

Mozuraite, V. (2014). Change of the reading paradigm in the age of e-book. Libellarium, 1(8), 83-91.

Naveed-e-Sehar, \& Ghaffar, A. (2018). Reading habits among undergraduate students of NED University of Engineering and Technology, Karachi, Pakistan: A pilot study. Library Philosophy and Practice, $1-9$.

Nuryaman. (2017). Persepsi peserta didik kelas sepuluh SMA Pasundan 3 Bandung terhadap implementasi gerakan literasi sekolah. In Seminar Nasional dan Call for Papers Prodi Ilmu Perpustakaan UM 2017 (pp. 123-139). Malang: Perpustakaan Universitas Negeri Malang.

Owusu-acheaw, M., \& Larson, A. G. (2014). Reading habits among students and its effect on academic performance: A study of students of Koforidua Polytechnic. Library Philosophy and Practice, 6(5), 1-24.

Petrovsky, D., Cacchione, P. Z., \& George, M. (2015). Review of the effect of music interventions on symptoms of anxiety and depression in older adults with mild dementia. International Psychogeriatrics, 27(10), 1661-1670. https://doi.org/ $10.1017 / \mathrm{S} 1041610215000393$

Sen, B. K. (2008). Ranganathan' s five laws. Annals of Library and Information Studies, 55(June), 87-90.

Seo, H.-S., Hahner, A., Gudziol, V., Scheibe, M., \& Hummel, T. (2012). Influence of background noise on the performance in the odor sensitivity task: effects of noise type and extraversion. Springer, 222, 89-97. https://doi.org/10.1007/s00221-012-32225

Shimray, S. R., Keerti, C., \& Ramaiah, C. K. (2015). An overview of mobile reading habits. Journal of Library \& Information Technology, 35(5), 343-354. https://doi.org/10.14429/djlit.35.5.8901 
Soroya, S. H., \& Ameen, K. (2016). Reading trends of youth in Pakistan: A pilot study. Pakistan Journal of Information Management \& Libraries (PJIM\&L), 17(2016), 86-97.

Su, Y. N., Kao, C. C., Hsu, C. C., Pan, L. C., Cheng, S. C., \& Huang, Y. M. (2017). How does Mozart's music affect children's reading? the evidence from learning anxiety and reading rates with e-books. Educational Technology \& Society, 20, $101-112$.

Sugiyono. (2016). Metode penelitian kuantitatif kualitatifR\&D. Bandung: Alfabeta.

Thoma, M. V, Marca, R. La, Brönnimann, R., Finkel, L., Ehlert, U., \& Urs, M. (2013). The effect of music on the human stress response. PLOS ONE, 8(8), 1-13. https://doi.org/10.1371/journal.pone.0070 156
Vandenhoek, T. (2013). Screen reading habits among university students. International Journal of Education and Development Using Information and Communication Technology (IJEDICT, 9(2), 37-47.

Waas, N. (2017). Pengaruh musik terhadap kenyamanan membaca mahasiswa di perpustakaan ISI Yogyakarta. Institut Seni Indonesia Yogyakarta. Retrieved from http://digilib.isi.ac.id/1733/ 


\section{DAFTAR GAMBAR}

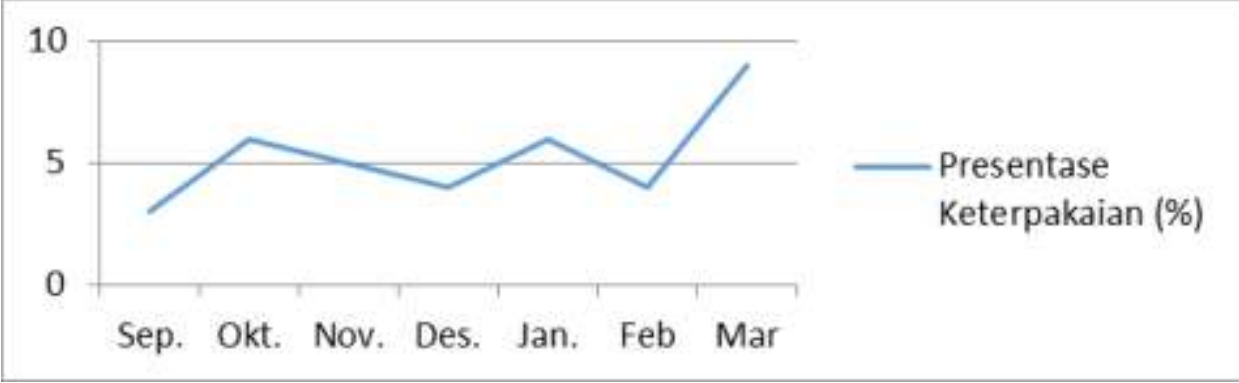

Gambar 1. Keterpakaian Koleksi Buku Teks oleh Pemustaka

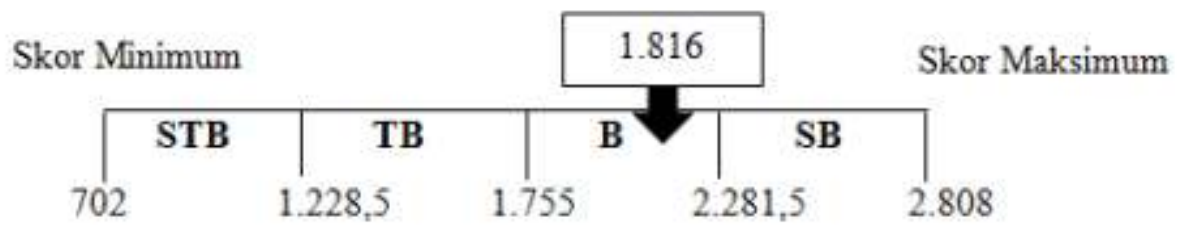

Gambar 2. Gambaran Persepsi Pemustaka terhadap Pemutaran Musik Instrumental

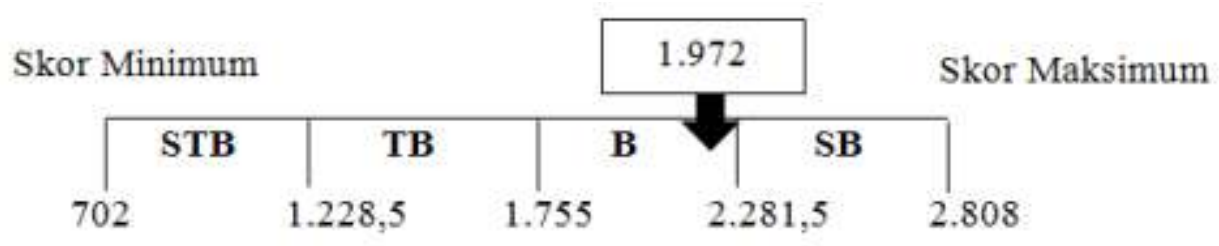

Gambar 3. Gambaran Kenyamanan Membaca Pemustaka 


\section{DAFTAR TABEL}

Tabel 1. Model Summary Data Variabel

\begin{tabular}{ccccc}
\hline Model & $\mathrm{R}$ & $\begin{array}{c}\mathrm{R} \\
\text { Square }\end{array}$ & $\begin{array}{c}\text { Adjusted R } \\
\text { Square }\end{array}$ & $\begin{array}{c}\text { Std. Error of the } \\
\text { Estimate }\end{array}$ \\
\hline 1 & ${\text {, } 403^{\mathrm{a}}}^{\mathrm{n}}$ &, 163 &, 147 & 7,35510 \\
\hline Sumber: Hasil Perhitungan menggunakan IBM SPSS 20 &
\end{tabular}

Sumber: Hasil Perhitungan menggunakan IBM SPSS 20

Tabel 2. Hasil Uji ANOVA ${ }^{\mathrm{a}}$

\begin{tabular}{rlrrrrr}
\hline \multicolumn{1}{c}{ Model } & Sum of Squares & df & Mean Square & F & Sig. \\
\hline \multirow{2}{*}{$1 \quad$ Regression } & 546,358 & 1 & 546,358 & 10,100 &, $002^{\mathrm{b}}$ \\
& Residual & 2813,068 & 52 & 54,097 & & \\
& Total & 3359,426 & 53 & & \\
\hline
\end{tabular}

Sumber: Hasil Perhitungan menggunakan IBM SPSS 20

Tabel 3. Gambaran Coefficients Variabel

\begin{tabular}{|c|c|c|c|c|c|c|}
\hline & \multirow{2}{*}{ Model } & \multicolumn{2}{|c|}{ Unstandardized Coefficients } & \multirow{2}{*}{$\begin{array}{c}\text { Standardized } \\
\text { Coefficients } \\
\text { Beta } \\
\end{array}$} & \multirow{2}{*}{$\mathrm{t}$} & \multirow{2}{*}{ Sig. } \\
\hline & & $\mathrm{B}$ & Std. Error & & & \\
\hline \multirow{2}{*}{1} & (Constant) & 11,946 & 7,179 & & 1,664 & 102 \\
\hline & Pemutaran Musik & ,341 & , 107 & ,403 & 3,178 & ,002 \\
\hline
\end{tabular}

